\title{
Comparison of Gluteal Muscle Intramuscular Injection Sites of Japanese Healthy Subjects: Considerations for Optimal Insertion of Injection Needle Length
}

\author{
Shigeaki Masuda', Yuko Yasuhara², Tetsuya Tanioka², Asumi Atsuta3 ${ }^{3}$ Kazushi Motoki, \\ Kensaku Takase ${ }^{5}$, Rozzano C. Locsin ${ }^{2}$ \\ ${ }^{1}$ Faculty of Nursing, School of Medicine, Nara Medical University, Nara, Japan \\ ${ }^{2}$ Department of Nursing, Tokushima University Graduate School of Health Sciences, Tokushima, Japan \\ ${ }^{3}$ Departmentof Nursing, Institute of Biomedical Sciences, Tokushima University Graduate School, \\ Tokushima, Japan \\ ${ }^{4}$ Department of Clinical Laboratory, Medical Technology Division, Tokushima Prefectural Kaifu Hospital, \\ Tokushima, Japan \\ ${ }^{5}$ Department of Neurosurgery, Tokushima Prefectural Central Hospital, Tokushima, Japan \\ Email: masuda@naramed-u.ac.jp
}

Received 4 March 2016; accepted 26 April 2016; published 29 April 2016

Copyright (C) 2016 by authors and Scientific Research Publishing Inc.

This work is licensed under the Creative Commons Attribution International License (CC BY).

http://creativecommons.org/licenses/by/4.0/

c) (i) Open Access

\section{Abstract}

Long Acting Injectable (LAI) medications for patients with schizophrenia is commonly administered to relieve their symptoms. Through shared decision-making and clinical evidence-based, psychiatrists should systematically offer LAIs to all patients requiring long-term antipsychotic treatment as a first-line treatment. Gluteal intramuscular (IM) injection requires accurate insertion of needles into the specific muscle area, often the outer upper quadrant of the buttocks, in order to achieve the required blood concentration. The purposes of this study were to compare the "Distance from the Epidermis to the Under-Fascia (DEUF)" and "Distance from the Epidermis to the Iliac Bone (DEB)" of the buttocks IM injection sites at the dorsogluteal and ventrogluteal sites among healthy Japanese volunteer subjects, and to identify the optimal insertion injection needle length. The DEUF and DEB at the gluteal regions were measured by ultrasonography. Welch's one-way analysis of variance was used to compare the DEUF and the DEB at the gluteal IM injection regions. There was no statistically significant difference observed between the right and left mean values of DEUF for Hochstetter and Clark's point at the ventrogluteal sites, and the Four and Three-way split or Double Cross point at the dorsogluteal sites. However in the DEB, the Hochstetter's point $(P<0.01)$ at ventrogluteal site on the right side, and Clark's point $(P<0.05)$ were significantly shorter than the Double Cross point at dorsogluteal sites $(F=4.38)$. The left buttocks 
Hochstetter's point was significantly shorter than the Double Cross point $(F=4.38, P<0.01)$. These results, however, did not establish a statistically significant difference in the DEUF among injection sites. It was considered that the difference in the DEB depended on muscle volume and thickness in the gluteal injection sites.

\title{
Keywords
}

\author{
Intramuscular Injection, Dorsogluteal, Ventrogluteal, Ultrasonography, Distance from the \\ Epidermis to the Under-Fascia, Distance from the Epidermis to the Iliac Bone, Optimal Insertion \\ Injection Needle Length
}

\section{Introduction}

Long Acting Injectable (LAI) Intramuscular (IM) injection in patients with schizophrenia is commonly needed to relieve their psychiatric symptoms [1]. Also, in an evidence-based clinical approach, psychiatrists should be systematically offering to all patients that require long-term antipsychotic treatment, through shared decision-making, a LAI antipsychotic as a first-line treatment [2].

LAI drugs used to treat schizophrenic patients are gradually absorbed and remain in the muscle tissue for approximately 2 - 4 weeks [1]. In cases if injected chemical solution remains in subcutaneous tissue and does not reach into the muscle, this can cause tissue damage as injection site skin reaction [3] [4]. An IM injection must be accurately and directly inserted into the central area of a specific muscle. This route of administration provides rapid absorption of medications thus enhancing the effects of the medications [5].

Yalcin et al. [6] showed that the distance at the dorsogluteal and ventrogluteal injection sites all point to the sciatic nerve. Sato et al. [7] examined injection needle for sites relationship between the superior gluteal nerve using direct observational data through dissection of the human body showing the two gluteal IM injection sites; "Four and three-way split" and "The point of Clark". Nurten et al. [8] investigated whether or not there is any anatomical vessel or neural structure present, while also determining the thickness of subcutaneous tissue, musculus gluteus medius, and the gluteus minimus muscles.

In Japan, Yasuhara et al. [5], Sakamaki et al. [9], and Tanioka et al. [10] measured by ultrasonography the optimal injection needle length for dorsogluteal IM injection sites among Japanese volunteer subjects. Similarly, Takahashi et al. [11] measured the subcutaneous tissue thickness of Hochstetter's site. Currently, however, there are no studies with Japanese subjects that show comprehensive comparisons of the "Distance from the Epidermis to the Under-Fascia (DEUF)" and the "Distance from the Epidermis to the Iliac Bone (DEB)" at the four IM injection sites as aforementioned.

The Four and Three-way split method is used as injection sites which are identified by Japanese researchers thereby recognizing the need to clarify the difference between those areas that are identified by foreign researchers and those of the Japanese counterparts [12]. The DEUF and DEB injection of the lateral part in the buttocks sites vary depending on the nurse's assessment.

The superior gluteal artery, the largest branch of the internal iliac artery accompanies the corresponding nerve under the gluteus maximus, and divides into branches that supply the gluteal muscles [13] [14]. The dorsogluteal injection sites are located major nerves and blood vessels in this area, including the sciatic nerve and superior gluteal artery [15] [16], therefore nurses must accurately identify landmarks to ensure accurate injection of needle to the correctly specified muscle [17]. Revealing the differences between these sites' DEUF and DEB will prevent the contact of the injection needle with the surface of the iliac bone, and lead to appropriately administer an accurate delivery of intramuscularly administer drug.

The purposes of this study are to compare the DEUF and DEB of IM injection sites at the dorsogluteal and ventrogluteal sites of the buttocks among Japanese healthy volunteer subjects; and to discuss about an optimal insertion injection needle length.

\section{Materials and Methods}

\subsection{Subject}

The subjects were recruited 5 persons each of male and female in age groups of the 50s from 20s respectively. 
Inclusion criteria included healthy subjects between the ages of 20 to 70 years with a stable body weight. Exclusion criteria included pregnant or lactating women or use of medications or injection sites in skin disorders known to affect metabolism.

\subsection{Study Period}

A comparative descriptive designs and period was conducted on July 11 and 12, 2015.

\subsection{Measures and Statistical Methods}

\subsubsection{Measurement by Ultrasonography}

The DEUF and DEB at the gluteal regions were measured by ultrasonography. All ultrasonographic measurements were performed by an experienced Sonographer using a $7.5 \mathrm{MHz}$ linear and convex array transducer and ultrasonograph diagnostic system (Hitachi Medical Corporation, Japan). Figure 1 is an example of ultrasonographic image [18].

Dorsogluteal sites were measured with a prone position: To identify the injection site using the "Four and Three-way split”, method, the selected buttocks area was imaginarily divided into four quadrants. The specified method of locating the injection site, was identified the upper outer quadrant [19], and at one third the distance from the iliac crest on the imaginary 45 degree line "Double Cross region". The "Double Cross" method divides the buttocks with an imaginary cross then divide the upper outer quadrant by another imaginary cross.

Ventrogluteal sites were measured with a lateral position, angles of an articulatio genus was about 90 to 100 degree: To identify the injection site by the "Hochstetter" method, place the palm of your hand over the trochanter. Point the first or index finger toward the anterior iliac crest. Spread the second or middle finger toward the back, making a "V". The thumb should be pointed toward the front of the leg. Injection site is between the knuckles on index and middle fingers. "The point of Clark" is located at the anterior one of the points trisecting the line connecting an antero-superior iliac spine and posterior superior iliac spine.

\subsubsection{Analysis Method}

Welch's one-way analysis of variance as used, to compare the DEUF and the DEB at the gluteal IM injection regions: "Four and Three-way split", "Double Cross", "Hochstetter" and "Clark" points. Statistical analysis of data was performed using SPSS (Ver. $21.0 \mathrm{~J}$ ). $\mathrm{P}<0.05$ was considered to be significant. The Welch's ANOVA procedure is frequently recommended as the major alternative to the ANOVA F test [20], and does not assume equal variances. This study had four groups: Four and Three-way split, Double Cross, Hochstetter, and Clark. The minimum sample size required each group at least 20 persons.

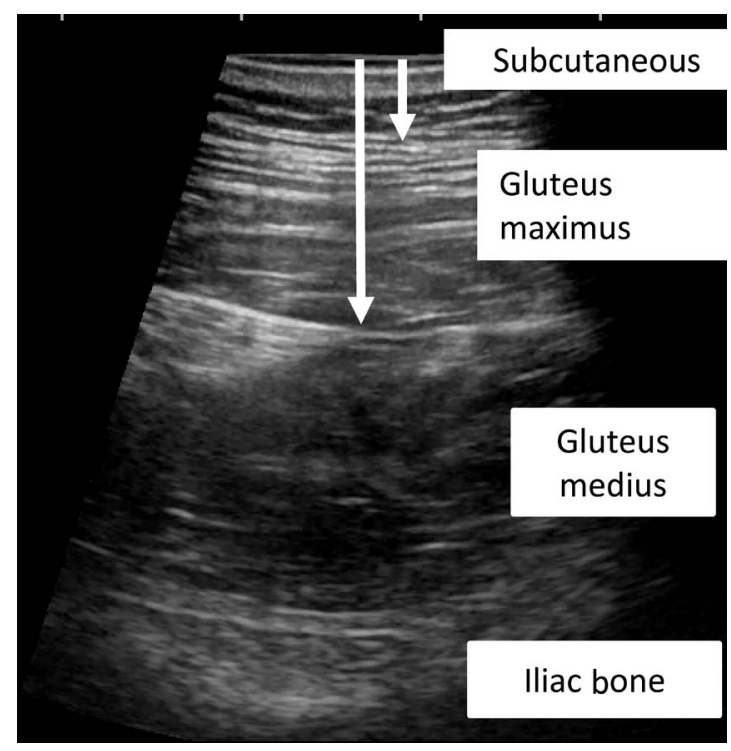

Figure 1. Example of ultrasonographic image. 


\subsection{Ethical Consideration}

This research was conducted with the approval (approval number 2948) of the Ethical Committee of the Tokushima University Hospital. Researchers explained the purpose, contents and method of this research study verbally and in writing to the prospective subjects. Those who consented to participate were regarded as subjects. The following were described in the consent letter: 1) the subjects' agreement to participate out of their own free will; 2) if they agree to participate in this research, they can discontinue it at any time and; 3) no disadvantage will be caused by cancellation of participation and cooperation.

\section{Results}

\subsection{The Characteristics and DEUF/DEB}

Table 1 shows the basic information regarding the subjects of the study. There were 39 healthy adult Japanese subjects (21 men and 18 women), with ages ranging from twenty to seventy (Mean \pm SD: $44.97 \pm 15.20$ years old; men $45.24 \pm 15.49$ years old; women $44.67 \pm 15.30$ years old). The average Body Mass Index (BMI) was $21.87 \pm 3.02 \mathrm{~kg} / \mathrm{m}^{2}$, with a minimum value of $17.20 \mathrm{~kg} / \mathrm{m}^{2}$ and a maximum of $29.00 \mathrm{~kg} / \mathrm{m}^{2}$.

Table 2 and Table 3 show the number of subjects of the groups regarding the depth of DEUF and DEB at the injection sites.

\subsection{The Comparison Results of DEUF and DEB}

These results show that the mean values of DEUF which have no significant differences on both the right and left gluteal sites at the Hochsteter (the right side: $14.37 \pm 7.28 \mathrm{~mm}$, the left side: $14.54 \pm 8.42 \mathrm{~mm}$ ), and Clark sites (the right side: $13.98 \pm 7.33 \mathrm{~mm}$, the left side: $14.88 \pm 7.67 \mathrm{~mm}$ ); the ventrogluteal sites, the point of Four

Table 1. Characteristics of physical information.

\begin{tabular}{|c|c|c|c|c|c|c|c|}
\hline & Item & & & Mean & Standard Deviation & Minimum & Maximum \\
\hline \multirow{4}{*}{ Basic Information } & \multicolumn{3}{|c|}{ Age } & 44.97 & 15.20 & 20.00 & 68.00 \\
\hline & \multicolumn{3}{|c|}{ Height (cm) } & 165.77 & 8.44 & 148.00 & 184.00 \\
\hline & \multicolumn{3}{|c|}{ Weight (kg) } & 60.75 & 12.49 & 40.50 & 94.70 \\
\hline & \multicolumn{3}{|c|}{ BMI $\left(\mathrm{kg} / \mathrm{m}^{2}\right)$} & 21.87 & 3.02 & 17.20 & 29.00 \\
\hline \multirow{16}{*}{$\begin{array}{l}\text { Measurement by } \\
\text { ultrasonography }\end{array}$} & \multirow{4}{*}{ Hochsteter } & \multirow{2}{*}{ Left } & DEUF (mm) & 11.89 & 4.71 & 4.30 & 22.90 \\
\hline & & & DEB (mm) & 52.88 & 9.59 & 36.00 & 75.30 \\
\hline & & \multirow{2}{*}{ Right } & DEUF (mm) & 12.53 & 4.78 & 5.00 & 25.00 \\
\hline & & & $\mathrm{DEB}(\mathrm{mm})$ & 54.30 & 9.80 & 35.30 & 74.10 \\
\hline & \multirow{4}{*}{ Clark } & \multirow{2}{*}{ Left } & DEUF (mm) & 12.15 & 4.39 & 4.60 & 26.00 \\
\hline & & & $\mathrm{DEB}(\mathrm{mm})$ & 56.52 & 8.98 & 43.80 & 74.50 \\
\hline & & \multirow{2}{*}{ Right } & DEUF (mm) & 12.30 & 5.25 & 5.30 & 28.20 \\
\hline & & & $\mathrm{DEB}(\mathrm{mm})$ & 55.71 & 8.93 & 38.10 & 76.30 \\
\hline & \multirow{4}{*}{$\begin{array}{c}\text { Four and } \\
\text { Three-way split }\end{array}$} & \multirow{2}{*}{ Left } & DEUF (mm) & 13.35 & 4.72 & 6.10 & 32.10 \\
\hline & & & DEB (mm) & 58.82 & 11.53 & 40.30 & 84.10 \\
\hline & & \multirow{2}{*}{ Right } & DEUF (mm) & 13.69 & 6.17 & 5.00 & 33.50 \\
\hline & & & $\mathrm{DEB}(\mathrm{mm})$ & 58.99 & 11.59 & 31.00 & 86.60 \\
\hline & \multirow{4}{*}{ Double Cross } & \multirow{2}{*}{ Left } & DEUF (mm) & 13.16 & 4.80 & 6.10 & 27.80 \\
\hline & & & DEB (mm) & 61.98 & 11.01 & 43.80 & 86.70 \\
\hline & & \multirow{2}{*}{ Right } & DEUF (mm) & 13.12 & 4.73 & 6.10 & 30.10 \\
\hline & & & DEB (mm) & 61.95 & 10.45 & 42.10 & 82.80 \\
\hline
\end{tabular}

BMI: Body Mass Index.

DEUF: Distance from the Epidermis to the Under-Fascia. DEB: Distance from the Epidermis to the Iliac Bone.

$\mathrm{N}=39,55 \%$ (21) were male and $45 \%$ (18) were female. 
Table 2. Range of DEUF and distribution of the number of subjects.

\begin{tabular}{cccccc}
\hline \multicolumn{2}{c}{ Injectuion sites } & DEUF $<15 \mathrm{~mm}$ & $15 \mathrm{~mm} \leq$ DEUF $<20 \mathrm{~mm}$ & $20 \mathrm{~mm} \leq$ DEUF $<25 \mathrm{~mm}$ & DEUF $\geq 25 \mathrm{~mm}$ \\
\hline \multirow{2}{*}{ Hochsteter } & Left & 31 & 6 & 2 & 0 \\
& Right & 28 & 8 & 2 & 1 \\
\multirow{3}{*}{ Clark } & Left & 32 & 5 & 0 & 2 \\
Four and & Right & 28 & 8 & 2 & 1 \\
Three-way split & Left & 31 & 5 & 2 & 3 \\
\multirow{2}{*}{ Double Cross } & Right & 29 & 5 & 2 & 2 \\
& Left & 29 & 6 & 3 & 1 \\
\hline
\end{tabular}

DEUF: Distance from the Epidermis to the Under-Fascia.

$\mathrm{N}=39,55 \%$ (21) were male and $45 \%$ (18) were female.

Table 3. Range of DEB and distribution of the number of subjects.

\begin{tabular}{cccccc}
\hline \multicolumn{2}{c}{ Injectuion sites } & $30 \mathrm{~mm} \leq \mathrm{DEB}<40 \mathrm{~mm}$ & $40 \mathrm{~mm} \leq \mathrm{DEB}<50 \mathrm{~mm}$ & $50 \mathrm{~mm} \leq \mathrm{DEB}<60 \mathrm{~mm}$ & DEB $\geq 60 \mathrm{~mm}$ \\
\hline \multirow{2}{*}{ Hochsteter } & Left & 3 & 13 & 15 & 8 \\
& Right & 3 & 10 & 14 & 12 \\
\multirow{2}{*}{ Clark } & Left & 0 & 11 & 15 & 13 \\
Four and & Right & 1 & 12 & 15 & 11 \\
Three-way split & Left & 0 & 11 & 9 & 13 \\
\multirow{2}{*}{ Double Cross } & Light & 2 & 6 & 13 & 18 \\
& Right & 0 & 5 & 15 & 20 \\
\hline
\end{tabular}

DEB: Distance from the Epidermis to the Iliac Bone.

$\mathrm{N}=39,55 \%$ (21) were male and $45 \%$ (18) were female.

and Three-way split (the right side: $17.05 \pm 9.83 \mathrm{~mm}$, the left side: $16.91 \pm 8.99 \mathrm{~mm}$ ), and the point of Double Cross (the right side: $17.28 \pm 9.99 \mathrm{~mm}$, the left side: $17.31 \pm 9.84 \mathrm{~mm}$ ) of the dorsogluteal sites.

Figure 2 (data from right side of buttocks) and Figure 3 (data from left side of buttocks) show the comparative data of the results of DEUF and DEB. In these box plots, the top of the rectangle indicates the third quartile, a horizontal line near the middle of the rectangle indicates the median, and the bottom of the rectangle indicates the first quartile. With the DEB on the right gluteal sites, the mean values of the points of Hochsteter (54.30 \pm $9.80 \mathrm{~mm})$ and of Clark $(55.71 \pm 8.93 \mathrm{~mm})$ at the vrentrogluteal sites were significantly shorter than the point of Double Cross $(61.95 \pm 10.45 \mathrm{~mm})$ at the dorsogluteal sites $(\mathrm{F}=4.38, \mathrm{P}<0.01)$. Furthermore, at the DEB on the left gluteal site, the mean values of the point of Hochsteter $(52.88 \pm 9.59 \mathrm{~mm})$ at ventrogluteal sites were significantly shorter than the point of Double Cross $(61.98 \pm 11.01 \mathrm{~mm})$ at the dorsogluteal sites $(\mathrm{F}=5.37, \mathrm{P}<0.01)$. However, there were no significant differences observed at the dorsogluteal sites between the points of Four and Three-way split and of the Double Cross.

\subsection{Observation of the Gluteus Maximus in Each of IM Injection Site}

The DEUF is the distance from the epidermis to the gluteus medius muscle, however in the case of the injection sites, the gluteus maximus is often covered by the gluteus medius muscle, and its distance to the fascia of the gluteus maximus. Table 4 shows the observed percentage of gluteus maximus in each of IM injection site.

\section{Discussion}

The findings of the study showed that there were no significant differences in the DEUF on the left and right buttocks among the points of Hochsteter, of Clark at ventrogluteal sites, the point of Four and Three-way split, and of the Double Cross at the dorsogluteal sites. 


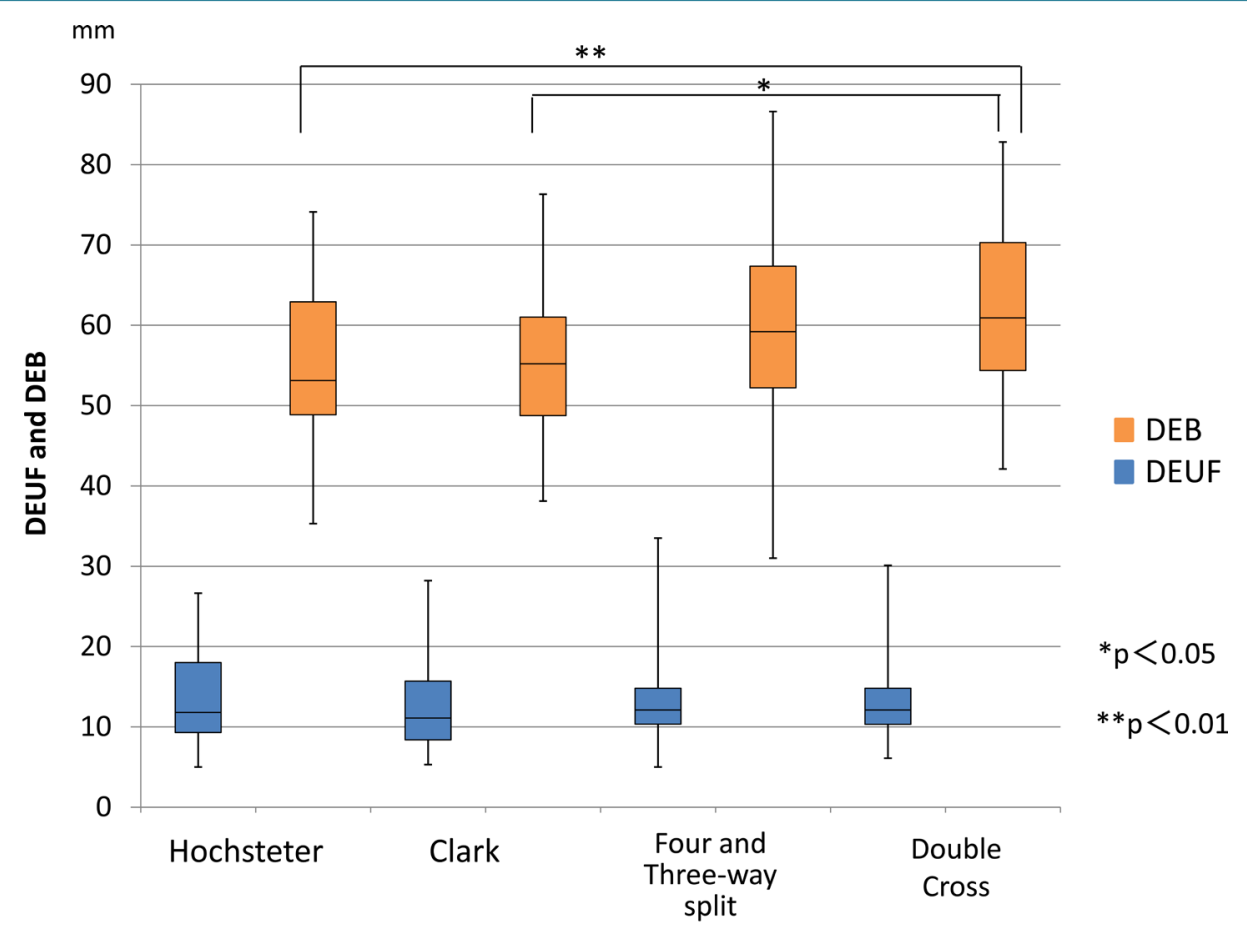

Figure 2. DEUF and DEB at each site on the right side.

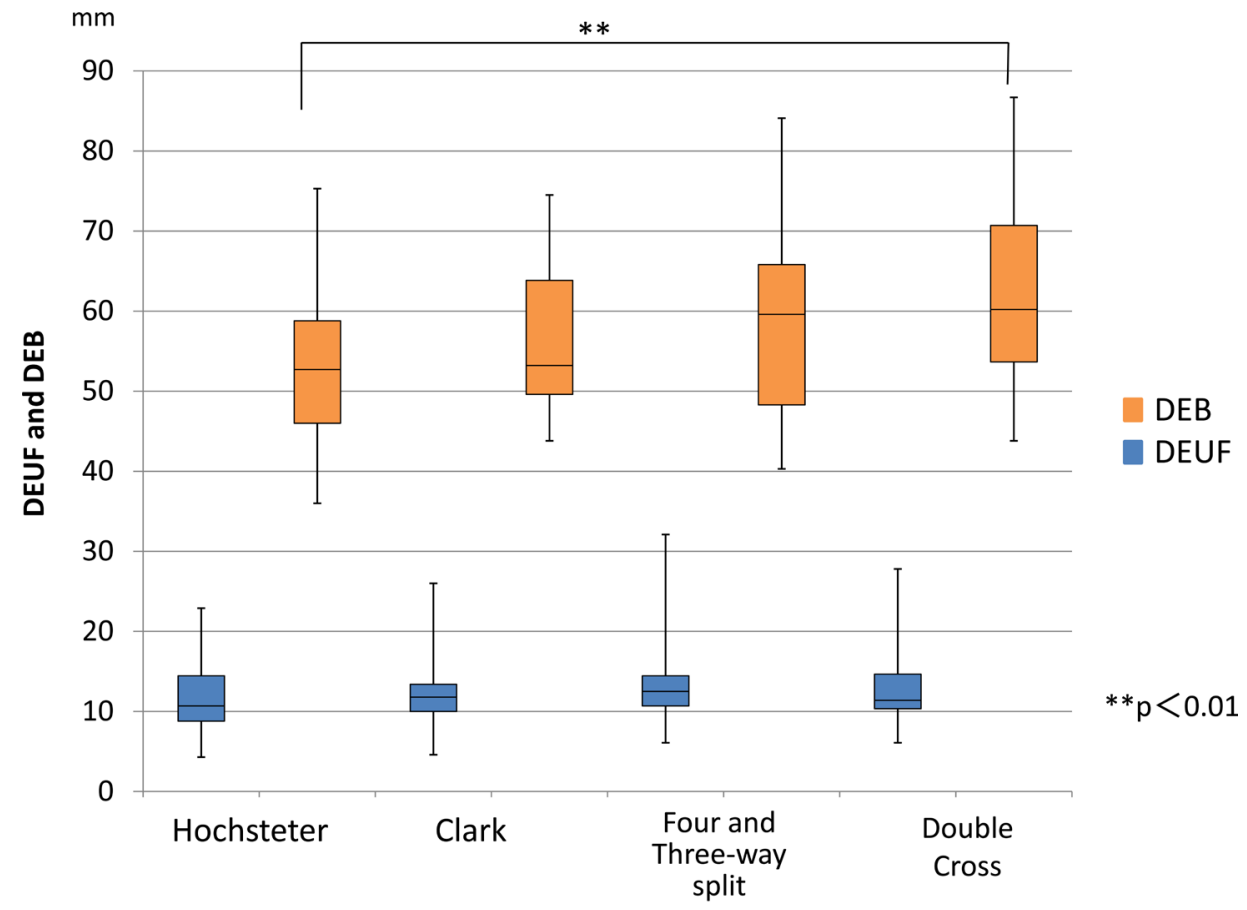

Figure 3. DEUF and DEB at each site on the left side.

Table 4. Number of subjects who observed gluteus maximus at the injection sites $(\mathrm{N}=39)$.

\begin{tabular}{|c|c|c|c|c|}
\hline & Four and Three-way split & Double Cross & Hochsteter & Clark \\
\hline Left side & 8 (20.5\%) & 8 (20.5\%) & 6 (15.4\%) & 7 (17.9\%) \\
\hline Right side & 7 (17.9\%) & 8 (20.5\%) & $4(10.3 \%)$ & $4(10.3 \%)$ \\
\hline
\end{tabular}


The BMI of the subjects were standard of Japanese body shape [21]. The mean values of DEUF at ventrogluteal sites were $14 \pm 8 \mathrm{~mm}$, and of the DEUF at dorsogluteal sites were $17 \pm 10 \mathrm{~mm}$. In this range, it was assumed that where the injection needle was inserted to a length between $15 \mathrm{~mm}$ and $25 \mathrm{~mm}$ in any points on both the right and the left buttocks, the point of the injection needle could reach into the muscle. Within the range of 18.5 $\leq \mathrm{BMI}<30.0 \mathrm{~kg} / \mathrm{m}^{2}$, which was shown by the results of the study of Takahashi et al. [11], was assumed that the point of the injection needle injected on the point of Hochsteter could reach into the muscle when the injection needle was inserted at $20 \mathrm{~mm}$ on both right and left buttocks. The maximum subject's BMI in this study was 29 $\mathrm{kg} / \mathrm{m}^{2}$, DEUF was less than $20 \mathrm{~mm}$. However, three subjects' DEUF were $20 \mathrm{~mm}$ or longer on the right buttocks, and two subjects' DEUF were $20 \mathrm{~mm}$ or longer on the left buttocks. Therefore, it was considered that injection with $20 \mathrm{~mm}$ insertion of the injection needle cannot reach in the gluteal muscle.

In this case, it may long residing depot can cause localized chronic-active inflammation in the tissue by subcutaneous injection [22].

While all of the subjects of this study were healthy, the subjects in the study of Takahashi et al. [11] included healthy people, and both in patients and outpatients. Therefore, there were differences in muscle volume and subcutaneous tissues. As Figure 2 and Figure 3 showed, DEB, on both right and left buttocks of the Hochsteter site at the ventrogluteal sites were shorter than the DEB of the Double Cross at dorsogluteal sites. There were no significant differences observed among the four injection points. Therefore, there is a high possibility that the tunica muscularis was thin, at the point just under the injection points for the Hochsteter sites. The mean values of DEB of the Hochsteter data ranged from $54.30 \pm 9.80 \mathrm{~mm}$ on the right buttocks and $52.88 \pm 9.59 \mathrm{~mm}$ on the left buttocks. Considering these inconsistencies in the physical characteristics of previous studies, people with standard body shape (as was in this study) were considered, in particular, to determine that the injection needle would not contact the iliac bone as long as it was less than approximately $45 \mathrm{~mm}$.

There were no significant differences observed in the DEB between the points of the Double Cross and the Four and Three-way split at the dorsogluteal sites. The mean values of DEB at the dorsogluteal sites ranged from $61.95 \pm 10.45 \mathrm{~mm}$ for Double Cross on the right buttocks and $61.98 \pm 11.01 \mathrm{~mm}$ on the left buttocks, and $58.99 \pm 11.59 \mathrm{~mm}$ for the Four and Three-way split on the right buttock, and $58.82 \pm 11.53 \mathrm{~mm}$ on the left buttock. Thereby, it was considered that the injection needle would not make contact with the iliac bone for persons with standard body proportions as long as the DEB ranged approximately from $50 \mathrm{~mm}$ to $60 \mathrm{~mm}$.

Sakamaki et al. [9] measured the Four and Three-way split positions of healthy subjects by ultrasonography. Their study showed that the mean value of the DEB were, in the case of persons with BMI of $<21 \mathrm{~kg} / \mathrm{m}^{2}, 67.46$ $\mathrm{mm}$ on the right buttocks, and $63.76 \mathrm{~mm}$ on the left buttocks, and, in the case of persons with BMI $\geq 21 \mathrm{~kg} / \mathrm{m}^{2}$, were $73.34 \mathrm{~mm}$ on the right buttocks and $70.17 \mathrm{~mm}$ on the left buttocks.

In comparison, this study recognized the difference was $10 \mathrm{~mm}$ or more. This could be because all the subjects of the Sakamaki et al's study were women and with ages ranging from forty years 70 , thereby the forms of muscle and fat were different seemingly due to the differences in gender and age.

Tanioka et al. [10] measured the Four and Three-way split positions of schizophrenic subjects by ultrasonography. The mean values of the DEB in the case of subjects with normal BMI $\left(18-25 \mathrm{~kg} / \mathrm{m}^{2}\right), 55.9 \mathrm{~mm}$ for the median value on the right side and $54.7 \mathrm{~mm}$ on the left, and, in the case of High BMI $>25 \mathrm{~kg} / \mathrm{m}^{2}$, a median value of $75.9 \mathrm{~mm}$ on the right side and $71.9 \mathrm{~mm}$ on the left side. The results of our study were much the same for normal BMI subjects. However, for the subjects with high BMI, there were differences observed of $10 \mathrm{~mm}$ or more. While 27 out of 37 subjects, in the study of Tanioka et al., had high BMI, 6 out of 39 subjects had high BMI in this study. Tanioka et al. [10] targeted the patients with schizophrenia, who reportedly [23] tend to be obese, and the mean values of DEB seemed to be longer with high BMI.

Textbooks [3] [24] in Japan at present instruct medical professionals to inject at 90 degrees, at 45 degrees, or within a range from 45 degrees to 90 degrees. This study concluded that the angle of needle during injection insertion was set at 90 degrees to the epidermis.

It would be difficult to guess exactly where the tip of the injection needle would reach, when the angle of insertion was not 90 degrees. Therefore, it would be probable that the tip of the injection needle would not reach tunica muscular is when two thirds or $30 \mathrm{~mm}$ [3] [24] of the injection needle, which was written in such textbooks, was inserted.

The IM injection techniques of nurses are not standardized, where some reference materials [25] even instruct that hypodermic injection, the purpose of which is to inject medicinal solution to subcutaneous tissue, had the same angle and depth for the insertion as IM injection. Assuming that an insertion distance of $30 \mathrm{~mm}$ is required 
in order to fully reach the tunica muscularis, when a $30 \mathrm{~mm}$ injection needle is inserted at an angle of 60 degrees, the actual distance shown was approximately $4 \mathrm{~mm}$ shorter than that of a $30 \mathrm{~mm}$ injection needle inserted at 90 degrees; a total $34.6 \mathrm{~mm}$ (adding $4.6 \mathrm{~mm}$ ) of insertion length is required to reach the same point (The calculation was made in the site of KEISAN. http://keisan.casio.jp/exec/system/1177477195). In addition to $4.6 \mathrm{~mm}$, referring to prior research [26], more additional distance (1 $\mathrm{mm}$ of tunica muscular is and $2 \mathrm{~mm}$ of blade face) is needed to reach the muscle; $30 \mathrm{~mm}$ plus a further $8 \mathrm{~mm}$. This means ordinary injection needle, 1.5 inches (38 $\mathrm{mm}$ ) may be impossible to reach the muscle.

Medicine solution and injection needles are specific to some products (for example, in Risperidone [27]) or specific injection needles (for example, in Paliperidone [28] or Aripiprazole [29]) are necessary when used clinically. Aripiprazole LAI requires a 1.5 inch $(38 \mathrm{~mm})$ injection needle [29] to be injected into the gluteus muscles and Risperidone requires a 2 inch $(50 \mathrm{~mm}$ ) [27] injection needle to be injected into the gluteus muscles. However, Paliperidone requires a 1 inch $(25 \mathrm{~mm})$ or 1.5 inch $(38 \mathrm{~mm})$ injection needle [28] to be injected into the deltoid muscle and/or the gluteus medius.

Tanioka et al. [26] pointed out that a 2 inch injection needle [27], which is specified for Risperidone, must be used carefully depending on body shapes with attention paid to the depth of insertion. Because insertion at any injection point have the risk of harm to the iliac bones the length of injection needle insertion must be taken into consideration in order to prevent the pointed tip of injection needles from hitting/touching the iliac bones. In the preceding study, [10] the subjects of which were patients with schizophrenia, did not have injection needles hitting/touching the iliac bone. Not only the insertion angle to the skin is critical but also the angle toward the iliac bone-would greatly influence whether or not the pointed tip of the injection needle would touch the iliac bone.

Prudent attention must be paid especially to the insertion in the region of Hochsteter, whose mean values of DEB are thin on both right and left buttocks. Therefore, nurses and doctors who administer these injections must give an IM injection in a proper manner based on sufficient consideration of these conditions.

The phase-1 study assessing the pharmacokinetics, safety, and tolerability of the investigational IM paliperidone palmitate, a 3-month formulation LAI in patients with schizophrenia or schizoaffective disorders has recently been started [30] [31]. More secure techniques, which could complications of injection sites caused by the chemical solution does not reach the muscle, must be developed for such LAI.

It was observed that some subjects had gluteus maximus muscle covering the gluteus medius muscle in the injection site regions. The basic method of IM injection targets the gluteus medius muscle [32] to avoid damage to nerves and blood vessels. Both the gluteus maximus muscle and gluteus medius muscle function to move the articulatio coxae; the gluteus maximus muscle is used to stretch the articulatio coxae, and the gluteus medius muscle functions mainly to stabilize the bony pelvis when walking. Nakajima et al. [33] formulated a new injection site close to Clark's point at ventrogluteal sites and found that the angle of the articulatio coxae flexion influenced the DEUF and the thickness of the gluteus medius muscle. Therefore, if IM injection performs in a lateral position at the ventrogluteal sites, it was considered that the relationship between angle of the articulatio coxae, contraction of muscle, and the length of DEUF and DEB are important factors.

\section{Conclusion}

The mean values of DEUF were not significantly different in all the hypodermic injection positions on both right and left buttocks. The DEB mean values on the right buttocks of the point of Hochsteter and of Clark at the ventrogluteal sites were significantly shorter than that of the Double Cross at the dorsogluteal sites, while the DEB mean values on the left buttocks of the point of Hochsteter at ventrogluteal sites were significantly shorter than that of the Double Cross at the dorsogluteal sites. Due to the differences in DEB length on the injection regions, the insertion angles of injection needle must be assessed on all the injection sites. In performing IM injection, it was very important to identify: 1) the body shape of subjects; 2), the thickness of the subcutaneous tissues; 3), the prescribed injection sites and; 4) the angle and depth of insertion. It was also important that for the insertion at ventrogluteal sites assessment of the posture of the subjects with full care and attention must also be critically considered.

\section{Limitation}

This study assessed the commonly prescribed muscle areas in currently used injection positions. However, while other studies had subjects with varying body shapes, the subjects of this study had standard body shapes. The 
examinations of patients with standard body shapes who had schizophrenia were needed to compare the IM injection effects using LAI medications.

\section{Acknowledgements}

The authors would like to thank the subjects of the study and all the staff members who have helped in this research study.

\section{References}

[1] Brissos, S., Veguilla, M.R., Taylor, D. and Balanzá-Martinez, V. (2014) The Role of Long-Acting Injectable Antipsychotics in Schizophrenia: A Critical Appraisal. Therapeutic Advances in Psychopharmacology, 4, 198-219. http://dx.doi.org/10.1177/2045125314540297

[2] Llorca, P.M., Abbar, M., Courtet, P., Guillaume, S., Lancrenon, S. and Samalin, L. (2013) Guidelines for the Use and Management of Long-Acting Injectable Antipsychotics in Serious Mental Illness. BMC Psychiatry, 13, 340. http://dx.doi.org/10.1186/1471-244x-13-340

[3] Takada, S. and Kawanishi, C. (2006) Injection Skills Based upon Evidence. Nakayama Shoten Co. Ltd., Tokyo, 123128. (In Japanese)

[4] Hamann, G.L., Egan, T.M., Wells, B.G. and Grimmig, J.E. (1990) Injection Site Reactions after Intramuscular Administration of Haloperidol Decanoate $100 \mathrm{mg} / \mathrm{ml}$. The Journal of Clinical Psychiatry, 51, 502-504.

[5] Yasuhara, Y., Hirai, E., Sakamaki, S., Tanioka, T., Motoki, K., Takase, K., Locsin, R., Kawanishi, C., Inui, T., Watari, C. and Makiguchi, K. (2012) Using Ultrasonography in Evaluating the Intramuscular Injection Techniques Used for Administering Drug Treatments to Schizophrenic Patients in Japan. The Journal of Medical Investigation, 59, $213-219$. http://dx.doi.org/10.2152/jmi.59.213

[6] Yalcin, E., Kose, S. and Akyuz, M. (2015) Comparing the Distances of Different Intramuscular Gluteal Injection Sites to the Sciatic Nerve. Journal of Novel Physiotherapy and Physical Rehabilitation, 2, 014-015.

[7] Sato, Y., Narita, S. and Nakano, T. (2005) A Study on the Method of Choosing Intramuscular Injection Site in the Buttocks. Journal of Japan Society of Nursing Research, 28, 45-52. (In Japanese)

[8] Kaya, N., Salmaslıoğlu, A., Terzi, B., Turan, N. and Acunaş, B. (2015) The Reliability of Site Determination Methods in Ventrogluteal Area Injection: A Cross-Sectional Study. International Journal of Nursing Studies, 52, 355-360. http://dx.doi.org/10.1016/j.ijnurstu.2014.07.002

[9] Sakamaki, S., Yasuhara, Y., Motoki, K., Takase, K., Tanioka, T. and Locsin, R. (2013) The Relationship between Body Mass Index, Thickness of Subcutaneous Fat, and the Gluteus Muscle as the Intramuscular Injection Site. Health, 5, 1443-1448. http://dx.doi.org/10.4236/health.2013.59196

[10] Tanioka, T., Sakamaki, S., Yasuhara, Y., Tomotake, M., Takase, K., Watari, C., Makiguchi, K., Locsin, R., Motoki, K. and Inui, T. (2013) Optimal Needle Insertion Length for Intramuscular Injection of Risperidone Long-Acting Injectable (RLAI). Health, 5, 1939-1945. http://dx.doi.org/10.4236/health.2013.512262

[11] Takahashi, Y., Kikuchi, K., Miura, N. and Ishida, Y. (2014) Appropriate Needle Insertion Depth for Intramuscular Injection Based on Assessment of BMI. Journal of Japan Academy of Nursing Science, 34, 36-45. (In Japanese) http://dx.doi.org/10.5630/jans.34.36

[12] Usui, H. (1972) Re-Examination of Injection Site. New Medical World Weekly, 1020, Tokyo. (In Japanese)

[13] Gilroy, A.M., MacPherson, B.R. and Ross, L.M. (2012) Atlas of Anatomy. Thieme Medical Publishers, Inc., New York, 462.

[14] Snell, R.S., Translated by Yamauchi, A. (2002) Snell Clinical Anatomy Clinical Anatomy: Clinical Anatomy for Medical Students. Medical Sciences International, Ltd., Tokyo, 585. (In Japanese)

[15] Small, S.P. (2004) Preventing Sciatic Nerve Injury from Intramuscular Injections: Literature Review. Journal of Advanced Nursing, 47, 287-296. http://dx.doi.org/10.1111/j.1365-2648.2004.03092.x

[16] Mishra, P. and Stringer, M.D. (2010) Sciatic Nerve Injury from Intramuscular Injection: A Persistent and Global Problem. International Journal of Clinical Practice, 64, 1573-1579. http://dx.doi.org/10.1111/j.1742-1241.2009.02177.x

[17] Greenway, K. (2014) Rituals in Nursing: Intramuscular Injections. Journal of Clinical Nursing, 23, 3583-3588. http://dx.doi.org/10.1111/jocn.12627

[18] Yasuhara, Y., Tanioka, T., Takase, K., Motoki, K., Watari, C., Makiguchi, K., Atsuta, A. and Locsin, R.C. (2016) Intramuscular Diffusion Status of Risperidone and Aripiprazole Long Acting Injectable (LAI) by Ultrasonography, Open Journal of Psychiatry, 165-172. http://dx.doi.org/10.4236/ojpsych.2016.62020

[19] Cornwall, J. (2011) Are Nursing Students Safe When Choosing Gluteal Intramuscular Injection Locations? Australa- 
sian Medical Journal, 4, 315-321.

[20] Jan, S.L. and Shieh, G. (2013) Sample Size Determinations for Welch’s Test in One-Way Heteroscedastic ANOVA. British Journal of Mathematical and Statistical Psychology, 67, 72-93.

[21] Ministry of Health, Labour and Welfare (2015) The National Health and Nutrition Survey in Japan, 2013. (In Japanese) http://www.mhlw.go.jp/bunya/kenkou/eiyou/dl/h25-houkoku.pdf

[22] Paquette, S.M., Dawit, H., Hickey, M.B., Merisko-Liversidge, E., Almarsson, O. and Deaver, D.R. (2014) Long- Acting Atypical Antipsychotics: Characterization of the Local Tissue Response. Pharmaceutical Research, 31, $2065-2077$. http://dx.doi.org/10.1007/s11095-014-1308-4

[23] Saiga, M., Watanabe, T. and Yoshioka, S. (2013) Physical and Mental Factors Associated with Obesity in Individuals with Mental Disorders Attending Psychiatric Day-Care Facilities. Yonago Acta Medica, 56, 1-6.

[24] Koyama, K., Joboshi, H., Asai, N. and Miki, S. (2006) Review of Safe Administration of Intramuscular Injection into Gluteus Mediusmuscle. Bulletin of Kiryu Junior College, 17, 181-188. (In Japanese)

[25] Gomi, C., Nakahashi, J., Kobayashi, T., Senba, M., Kobayashi, M., Taniguchi, T., Iguchi, K. and Mochizuki, A. (2009) The Analysis of the Description Contents of the Subtext in the Basic Nursing Technical Education about Technique of Subcutaneous Injection. Bulletin of Faculty of Nursing, Yamanashi Prefectural University, 11, 73-86. (In Japanese)

[26] Tanioka, T., Yasuhara, Y., Sakamaki, S., Masuda, S. and Takase, K. (2014) Safe Methods of Long-Acting Intramuscular Injection in Psychiatry. The Japanese Journal of Psychiatric Nursing, 41, 35-45. (In Japanese)

[27] Janssen Pharmaceutical K.K. (2015) Risperdal Consta Intramuscular Inj. (In Japanese) http://www.janssenpro.jp/cs/Satellite?pagename=jpro/BlobDspBody\&c=simage\&cid=1402062276447

[28] Janssen Pharmaceutical K.K. (2013) XEPLION Aqueous Suspension for IM Injection. (In Japanese) http://www.janssenpro.jp/cs/Satellite?pagename=jpro/BlobDspBody\&c=simage\&cid=1402065593382

[29] Otsuka Pharmaceutical Co., Ltd. (2015) ABILIFY. Prolonged Release Aqueous Suspension for IM Injection. (In Japanese) https://www.otsuka-elibrary.jp/di/prod/product/file/abk/abk_if.pdf

[30] Ravenstijn, P., Remmerie, B., Savitz, A., Samtani, M.N., Nuamah, I., Chang, C.T., De Meulder, M., Hough, D. and Gopal, S. (2016) Pharmacokinetics, Safety, and Tolerability of Paliperidone Palmitate 3-Month Formulation in Patients with Schizophrenia: A Phase-1, Single-Dose, Randomized, Open-Label Study. The Journal of Clinical Pharmacology, 56, 330-339. http://dx.doi.org/10.1002/jcph.597

[31] Berwaerts, J., Liu, Y., Gopal, S., Nuamah, I., Xu, H., Savitz, A., Coppola, D., Schotte, A., Remmerie, B., Maruta, M. and Hough, D.W. (2015) Efficacy and Safety of the 3-Month Formulation of Paliperidone Palmitate vs Placebo for Relapse Prevention of Schizophrenia: A Randomized Clinical Trial. JAMA Psychiatry, 72, 830-839. http://dx.doi.org/10.1001/jamapsychiatry.2015.0241

[32] Elaine, N.M. (2010) Essentials of Human Anatomy \& Physiology. Pearson Education, Inc., New York, 208-210.

[33] Nakajima, Y., Mukai, K., Komatsu, E., Iuchi, T., Kitayama, Y. and Nakatani, T. (2013) A Comparative Study between a Novel Intramuscular Injection Point in the Gluteal Muscle at $0^{\circ}, 45^{\circ}$ and $90^{\circ}$ Hip Joint Flexion and the Point of Clark in Living Bodies. Structure and Function, 11, 109-115. (In Japanese) 